Research Journal of Applied Sciences 13 (7): 431-438, 2018

ISSN: $1815-932 \mathrm{X}$

(C) Medwell Journals, 2018

\title{
Urban Territorial Accessibility Through Road Infrastructure Works and Betterment Levy Area
}

\author{
${ }^{1}$ Diego Alexander Escobar, ${ }^{1}$ Santiago Cardona and ${ }^{2}$ Carlos Alberto Moncada \\ ${ }^{1}$ Universidad Nacional de Colombia, Sede Manizales, Facultad de Ingeniería y Arquitectura, \\ Departamento de Ingeniería Civil, Carrera 27 \# 64-60, Manizales, 170004, Colombia. \\ ${ }^{2}$ Universidad Nacional de Colombia, Sede Bogotá, Faculta de Ingeniería, Departamento \\ de Ingeniería Civil y Agrícola, Ciudad Universitaria edificio 214 oficina 417, Bogotá, 111321, Colombia.
}

\begin{abstract}
This research analyzes urban territorial accessibility which allows to explore savings in travel time as an alternative to assess benefits derived from the development of transport infrastructure and their relationship with economic contributions charged to the benefited community (Betterment Levies). This methodology serves as a complement for entities that calculate Betterment Levy (BL) collection used, since, 1921 to finance infrastructure works in Colombian cities. A case study is made of The Carola intersection in the city of Manizales, calculating savings in travel time in the neighborhoods where BL collection will be made, demonstrating mobility benefits that can be generated and justified.
\end{abstract}

Key words: Accessibility, geostatistics, mobility, mean travel time, betterment levy, complement, Manizales

\section{INTRODUCTION}

Betterment Levies (BL) are a tool frequently used in Colombian cities, since, 1921 to finance urban infrastructure works that benefit the quality of life of its inhabitants (Ochoa, 2011). This contribution should be understood as an improvement of current real estate caused by the construction of a public work, rather than payment for its use (Fernandez, 1981). Manizales (Fig. 1), capital of the Colombian Department of Caldas, is a city located in the center west of the country on the Andes mountain range, $303 \mathrm{~km}$ from the capital, Bogota with about 415,000 inhabitants. Manizales has been a pioneer in the construction of transport infrastructure works through betterment levies (approximately 18 in the last 50 years). It has been through INVAMA (Instituto de Valorizacion de Manizales), a company operating, since, 1961, that infrastructure development has been managed. Developing and financing infrastructure projects using BL are among its responsibilities. It must also determine areas impacted by each project and calculate the amount to be charged depending on the value of each property. INVAMA uses an appraisal method to assess BL, taking into account) possible change in land use) mobility improvement) verifiable savings in travel time and distance and) decrease in pollution by emissions and congestion (Ochoa, 2011). Mobility improvement and verifiable savings in travel times are fundamental in the analysis of $\mathrm{BL}$ collection.
In this research, territorial accessibility is used as a method to check savings in average travel times produced by the construction of new transport infrastructure. Current and future scenarios are analyzed once the work is inaugurated in order to calculate travel time savings percentage, i.e., the gradient $(\mathrm{SG} \%)$. The Carola intersection (Fig. 2) is included in the Manizales Development Plan (2016-2019). It is a high traffic roundpoint intersection that seeks to reduce the congestion generated by the many conflicts between turns and direct traffic that are currently controlled with a traffic light. This traffic light is highly congested due to vehicle volume ( $>1,500$ vehicles per hour per lane) and low speed (below $10 \mathrm{~km} / \mathrm{h}$ ) during rush hour (17:45-18:45). The total cost of the project will be US $\$ 18$ million. Phase 1 is currently in progress, amounting to US $\$ 9$ million. INVAMA expects to raise US $\$ 6.76$ million through $\mathrm{BL}$ collection which represents $75 \%$ of the total infrastructure cost in phase I (Aguirre, 2016; Anonymous, 2017).

The term accessibility was defined in the middle of the last century as "the potential of opportunities for interaction". It was understood as an alternative for land planning studies and different land uses (Hansen, 1959). Advances were made in the late $70 \mathrm{~s}$, developing its mathematical part with different axioms that must be taken into account for calculation (Weibull, 1976). The concept has been changed over the years to include different perspectives such as analysis by age, gender, economy, mode of travel, etc. (Pirie, 1979; Handy and

Corresponding Author: Diego Alexander Escobar, Universidad Nacional de Colombia, Sede Manizales, Facultad de Ingeniería y Arquitectura, Departamento de Ingeniería Civil, Carrera 27 \# 64-60, Manizales, 170004, Colombia 


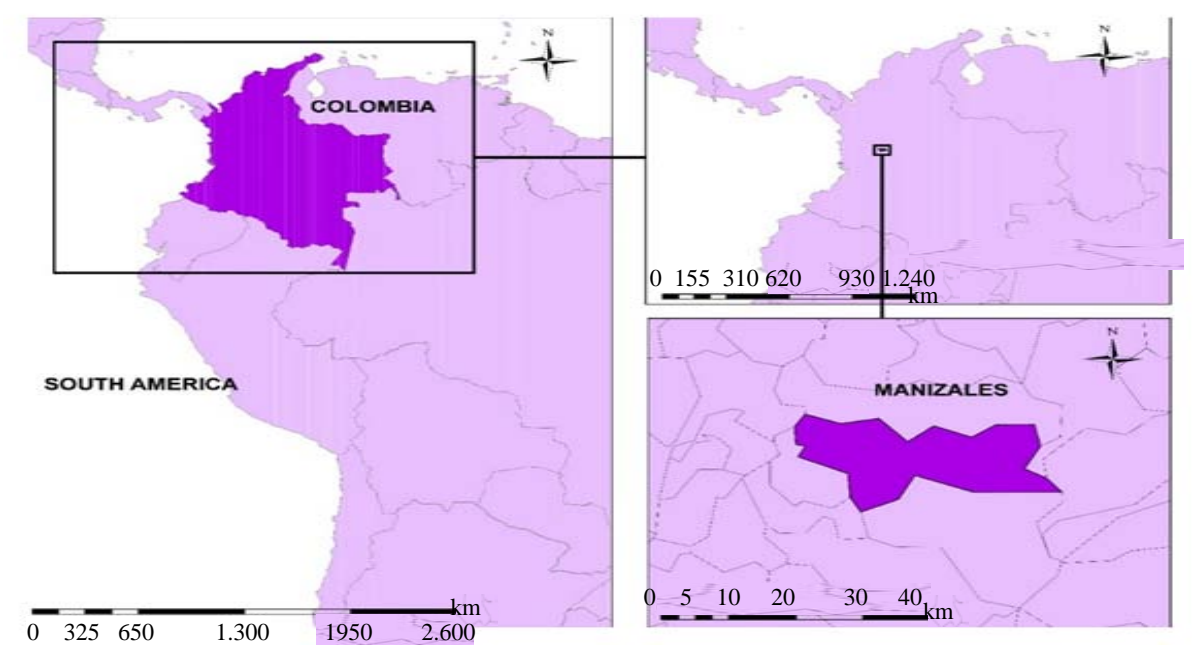

Fig. 1: Geographic location of the city of Manizales, Colombia

(a)

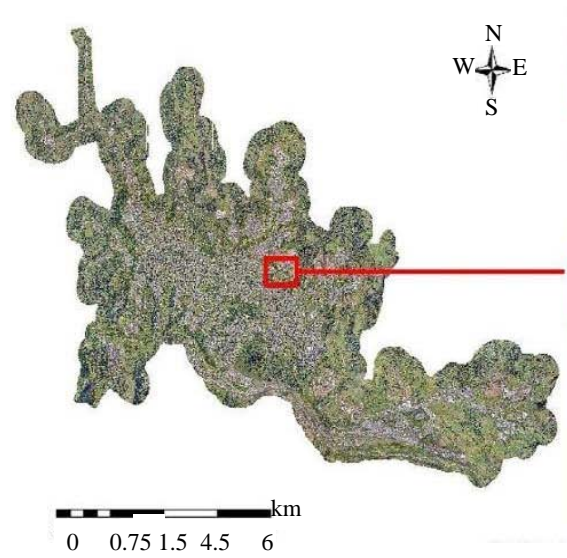

(b)

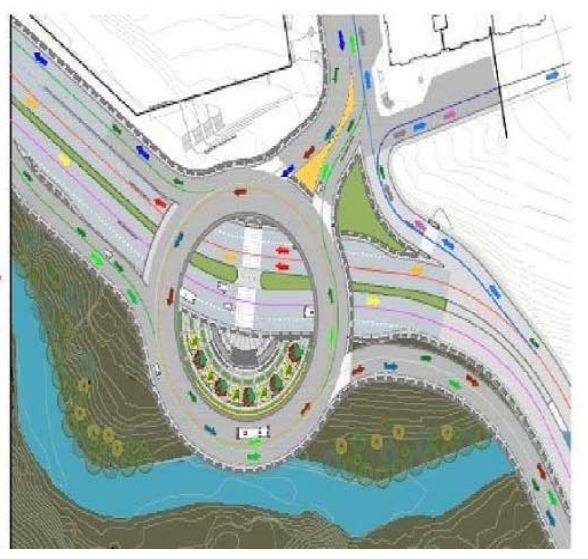

Fig. 2: Road interchange location "La Carola"

Niemeier, 1997). Its calculation has also evolved in hand with computing development and its aim. Some of the different type calculations are the comprehensive average accessibility, relative accessibility and global or territorial urban accessibility (Ingram, 1971). The latter was originally proposed by Geurs and Eck (2001), who called it "accessibility based on infrastructure" because it used the road network and average operating speed to calculate the mean travel time of users in the network and estimate its quality. Accessibility has been recently used in studies related to land planning (Geurs and Wee, 2004), sustainable transport development (Vega, 2011), analysis and planning of public transport (Gulhan et al., 2013), road re-routing studies (Escobar et al., 2016), land use and transport quality (Boisjoly and El-Geneidy, 2017), social exclusion (Preston and Raje, 2007), access to health systems (Escobar and Garcia, 2012), among others.
After brief introduction, the methodology of applied research will be addressed, followed by results and discussion before reaching main conclusions. References cited throughout the study are listed at the end.

\section{MATERIALS AND METHODS}

Research methodology used (Fig. 3) consists of 4 consecutive stages and a sub-step base of data collection and arrangement.

Throughout data collection, the road infrastructure network of the city was adjusted, verifying topology, connection between nodes (intersection between two roads), operating speeds on the arcs (road segments) and road directionality. The ArcGIS Geographic Information System was used. Operating speeds on the arcs were taken by Global Positioning System (GPS) 


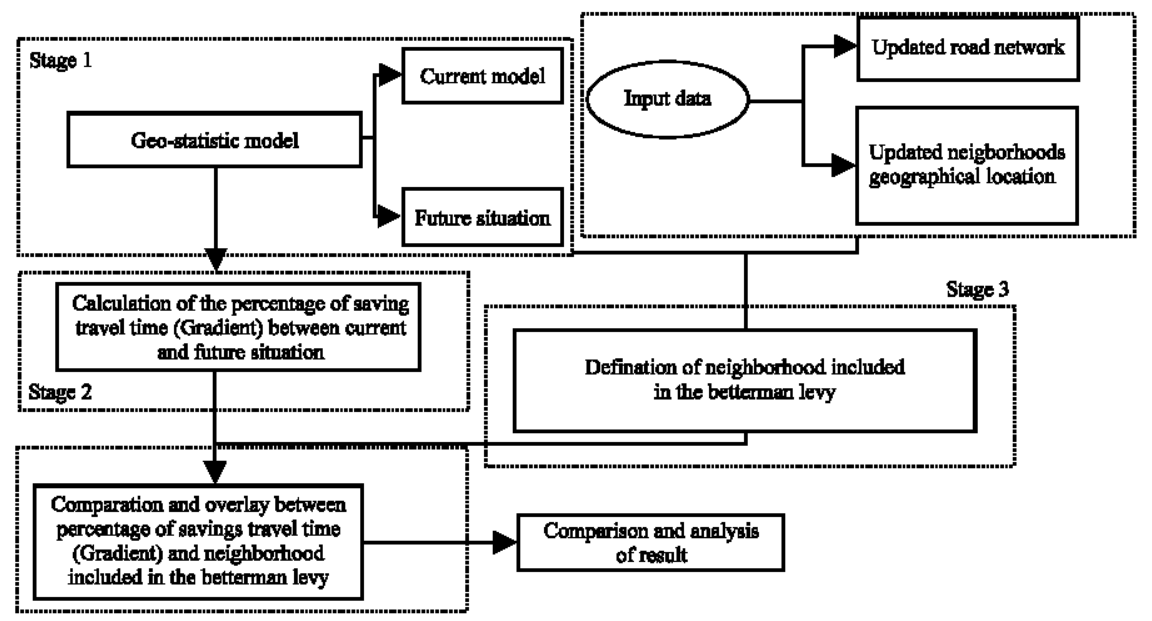

Fig. 3: Flow diagram, research methodology

installed in vehicles that crossed the network and calculated in 2012 within the framework of the city's Mobility Plan (Escobar and Garcia, 2012). The Carola intersection had to be geolocated and modifications were made in the current network to include it. Furthermore, the neighborhood polygon of the city had to be taken into account which includes information such as area, population and socio-economic stratum. Socio-economic stratum is a scale from 1-6 where 1-2 represent the lower strata, 3-4 medium strata and 5-6 high strata.

Stage 1; Geostatistical model for current and future scenarios: Urban territorial accessibility can be assessed from the current road infrastructure network in Manizales. Lowest travel times $\left(\mathrm{t}_{\mathrm{vi}}\right)$ from a node $\left(\mathrm{n}_{\mathrm{i}}\right)$ to the remaining nodes in the road network must be obtained. The Dkjistra algorithm of minimum paths is used, thus forming an array of average travel times where all network nodes are involved. This allows calculating the vector of average Travel times $\left(\mathrm{T}_{\mathrm{vi}}\right)$ (Escobar and Urazan, 2014). The equation used to calculate average travel times is expressed below Eq. 1:

$$
\mathrm{T}_{\mathrm{vi}}=\frac{\sum_{\mathrm{i}}^{\mathrm{n}} \mathrm{t}_{\mathrm{vi}}}{\mathrm{n}-1}
$$

For geo-statistical analysis, the ordinary Kriging method with linear semivariogram is used which has shown a lower error and better approximations related to a shorter distance between the points to be interpolated (Giraldo, 2002). Through this model, an interpolation is made between the average travel times calculated for each node of the network, making it possible to obtain the isochrones curves of territorial accessibility (Garcia and Bonells, 2014).
Stage 2; Saving percentage in average travel time (gradient, SG\%): This calculation is made with the results of territorial accessibility for current scenario (Atc) and future scenario (Atf) using the formula below. It results in the percentage of savings in travel times generated by the new infrastructure in the city and more particularly in the study area:

$$
\mathrm{SG} \%=\frac{\mathrm{AMGc}^{*}-\mathrm{AMGf}}{\mathrm{AMGC}} \times 100
$$

Stage 3; Definition of the neighborhoods included in the recovery contribution: Area of influence is defined by INVAMA. Figure 4 shows the neighborhoods included in $\mathrm{BL}$ collection according to the study carried out by the entity. Table 1 shows the number of subscribers per neighborhood: 15311 subscribers in 15 neighborhoods totaling an area of 524 hectares ( 29 subs/ha), close to $9 \%$ of Manizales (5868 ha). Socio-economic stratum is shown as well (Aguirre, 2016; Anonymous, 2017). Socio-economic stratum of each neighborhood is registered. The middle stratum is preponderant with 9 neighborhoods, followed by the low and high stratum with 3 neighborhoods each. The number of subscribers per hectare in each neighborhood is also registered.

Stage 4: After obtaining the $\mathrm{SG} \%$ of the city (stage 2) and the area defined by INVAMA for BL collection (stage 3), the $\mathrm{SG} \%$ of the influenced area can be extracted to perform the analysis for the generated savings in time due to the new intersection and the beneficiary population in the study area. 

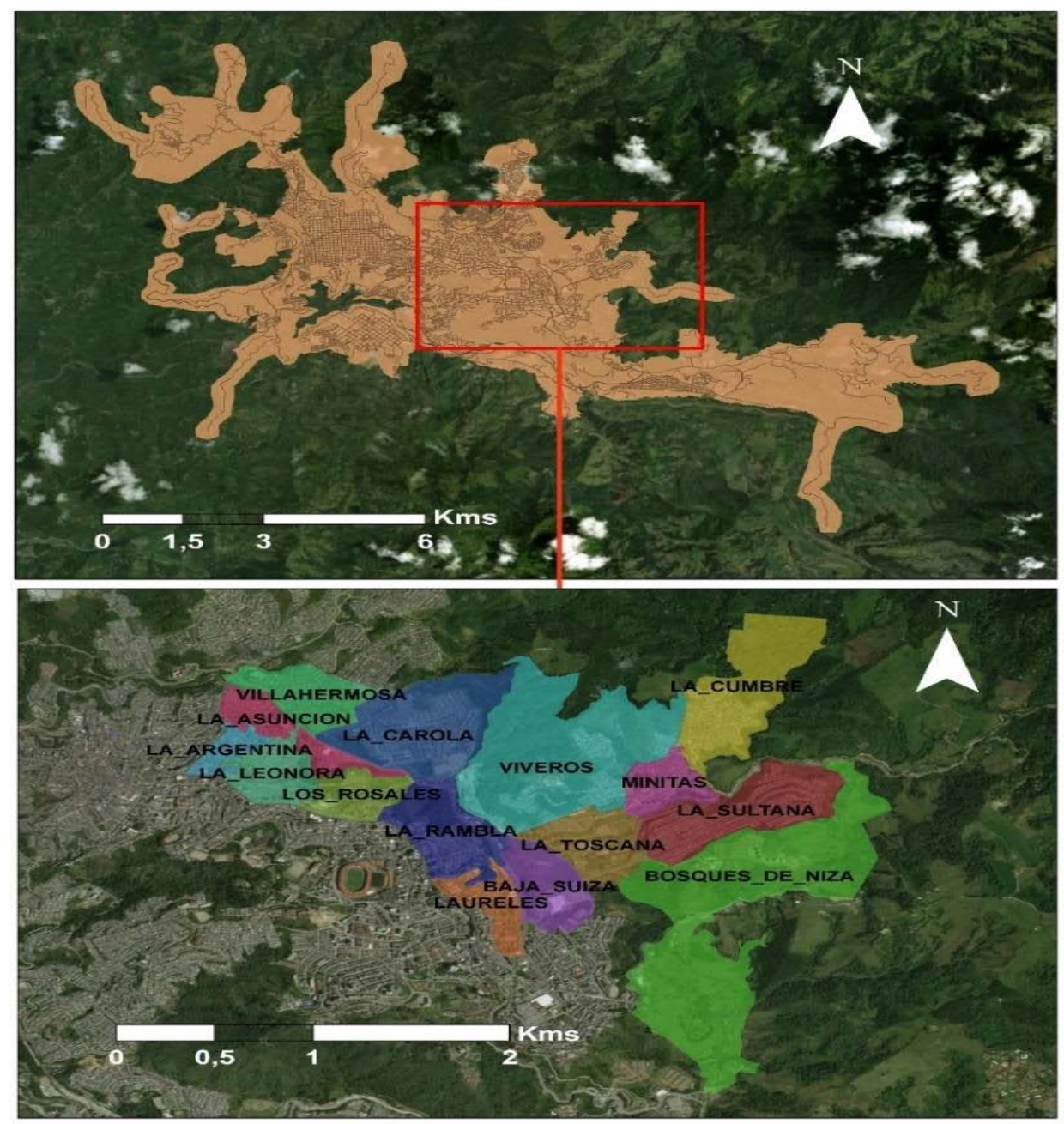

Fig. 4: Location of neighborhoods included in BL; Own elaboration made from data gathered from INVAMA

Table 1: Information of neighborhoods in the area of influence

\begin{tabular}{|c|c|c|c|c|c|}
\hline Neighborhood & Subscribers & Socio-economic strata & Area (ha) & Subscribers per area (Subs/ha) & Subscribers per area strata (Subs/ha/Str) \\
\hline La Cumbre & 1,220 & 2 & 45.1 & 27 & 113 \\
\hline Villa Hermosa & 1,669 & 2 & 21.8 & 77 & \\
\hline Viveros & 826 & 2 & 88.3 & 9 & \\
\hline La Argentina & 634 & 3 & 7.8 & 81 & 271 \\
\hline La Asuncion & 656 & 3 & 16.6 & 40 & \\
\hline La Carola & 2,682 & 3 & 48.2 & 56 & \\
\hline La Sultana & 1,794 & 3 & 40.0 & 45 & \\
\hline La Toscana & 163 & 3 & 22.9 & 7 & \\
\hline Minitas & 635 & 3 & 15.0 & 42 & \\
\hline Baja Suiza & 200 & 4 & 21.7 & 9 & 88 \\
\hline Bosques de Niza & 548 & 4 & 121.0 & 5 & \\
\hline La Leonora & 1,281 & 4 & 17.4 & 74 & \\
\hline La Rambla & 1,695 & 5 & 29.5 & 57 & 57 \\
\hline Laureles & 365 & 6 & 14.1 & 26 & 90 \\
\hline Los Rosales & 943 & 6 & 14.7 & 64 & \\
\hline Total & 15,311 & & 524.1 & 619 & \\
\hline
\end{tabular}

\section{RESULTS AND DISCUSSION}

The results obtained in stage 1 on urban territorial current accessibility (Fig. 5) show isochronous curves of approximately $25 \mathrm{~min}$ around Santander Avenue and Kevin Angel Avenue which are considered main arteries, and a high ranking times among 70 and $100 \mathrm{~min}$ for areas located in the periphery of the city which are indicated in 


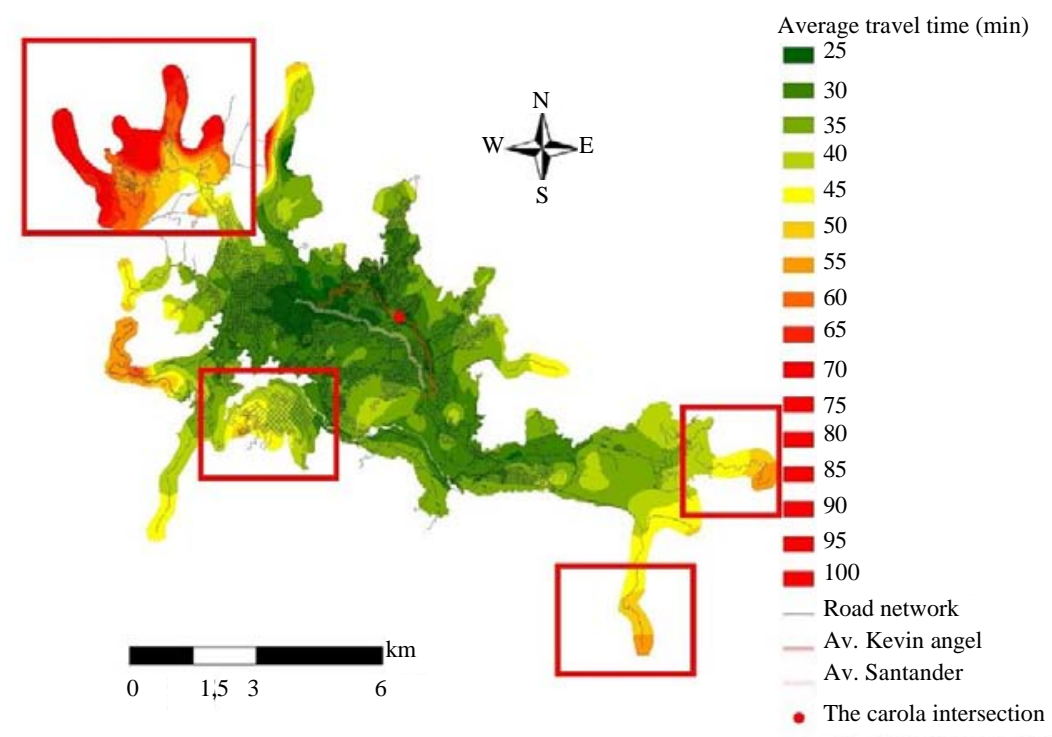

Fig. 5: Isochronous curves urban territorial accessibility current situation

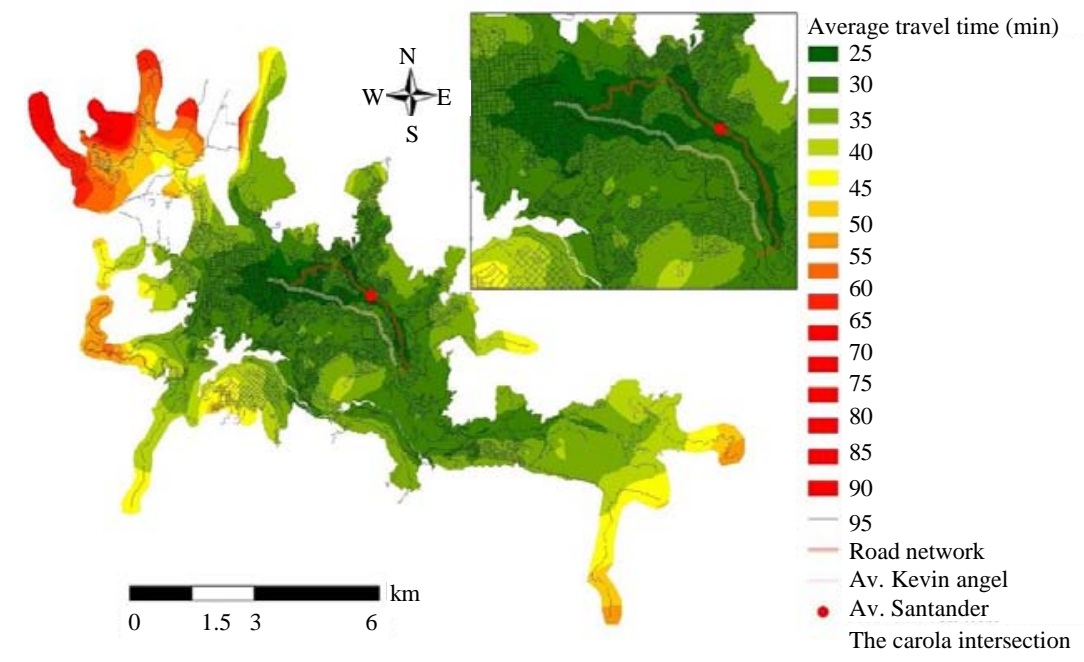

Fig. 6: Isochronous curves urban territorial accessibility future situation

Fig. 5 with boxes. The urban territorial accessibility for the future situation (Fig. 6) shows a growth in the percentage of area covered by the isochronous curves between 25,30 and $35 \mathrm{~min}$ that can be observed in more detail in Fig. 7. The box in Fig. 6 shows growth of the isochronous curve of $25 \mathrm{~min}$ around the new infrastructure. This represents a benefit in the average travel times accounted to it.

Furthermore, a decrease in the percentage of the covered area in the isochronous curve of 40 and $45 \mathrm{~min}$ can be evidenced in Fig. 7. Afterwards, the area percentages for the isochronous curves $>50 \mathrm{~min}$ are stabilized with very small variations between both

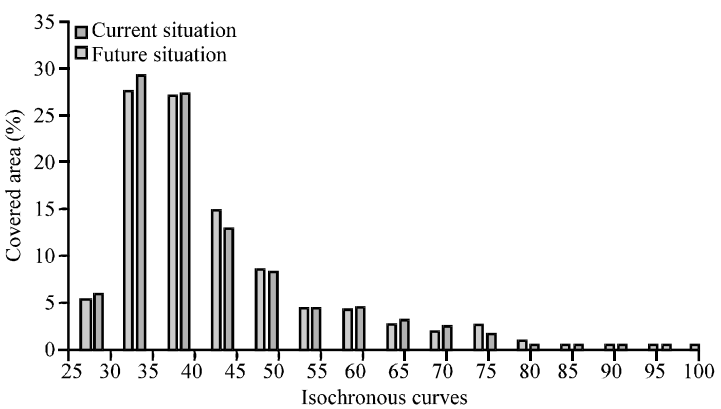

Fig. 7: Variation of percentage of covered area per isochronous curves between current and future situation 


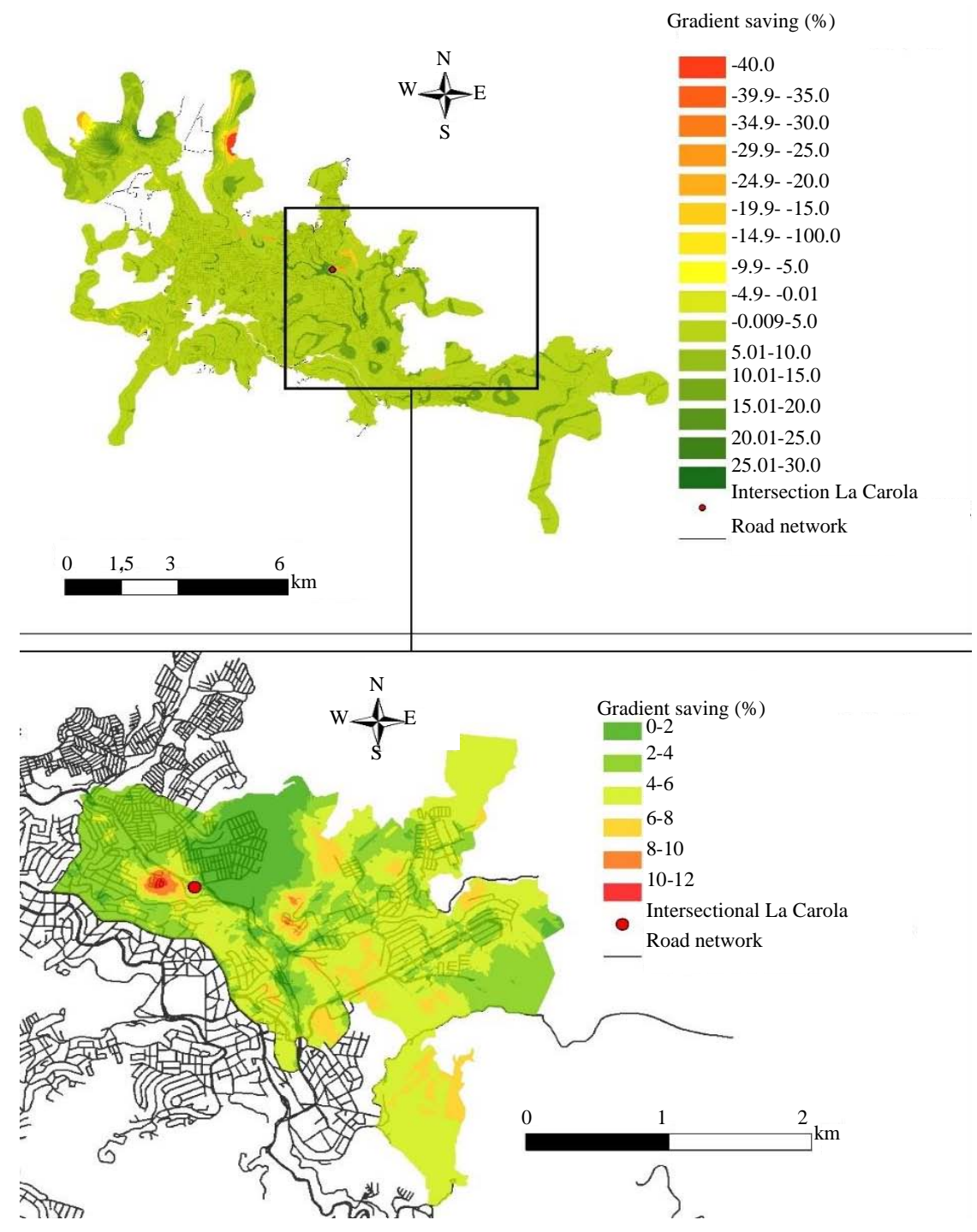

Fig. 8: Gradient saving (\%) city and neighborhoods included in the betterment levy

scenarios. The percentage gradient of average travel time saving calculated in stage 2 is presented in the upper part of Fig. 8. There are percentages that vary between -40 and $30 \%$. The areas affected by negative gradients are minuscule and do not represent more than $1 \%$ of the total area of the city ( $5868 \mathrm{ha})$. On the other hand, $95 \%$ of the population saves up to $5 \%$ in their average travel times and 30\% in North-Eastern areas of the city.

In the lower part of Fig. 8, saving percentages created by the Carola intersection in the neighborhoods of the area of influence can be seen. Maximum saving of $12 \%$ in the average travel times is reached while the minimum saving was $2 \%$. This evidences verifiable benefit in terms of mobility and time savings.
Figure 9 shows the relationship between the percentage of savings and the beneficiary population in the neighborhoods included. The graph displays how the higher the curve is for a higher percentage of savings, the more benefit in terms of savings in average travel time the population receives. In this sense, the population of the Laureles neighborhood which has 26 subs/ha was the most benefited, since, $80 \%$ of the neighborhood's population obtained up to $4 \%$ of time savings.

Furthermore, neighborhoods such as Minitas (42 subs/ha), La Toscana ( 7 subs/ha), La Rambla (57 subs/ha) and Bosques de Niza (5 subs/ha) also obtained percentages of population coverage between $60 \%$ and $70 \%$ with time savings of up to $4 \%$. On the other hand, neighborhoods such as Villa Hermosa which has a high 


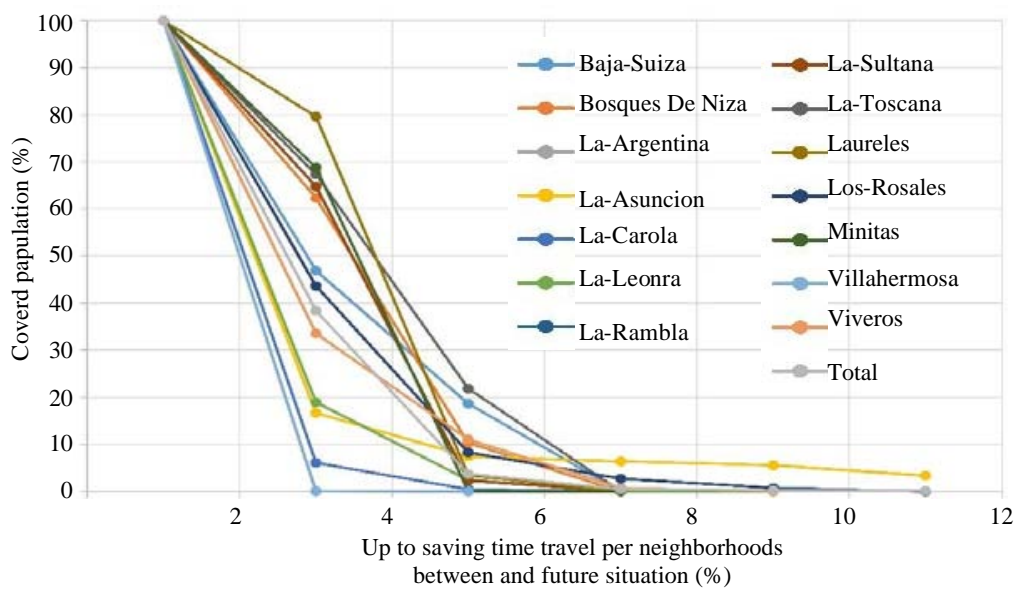

Fig. 9: Covered population vs. \% saving travel time per neighborhoods included in the betterment levy

number of subscribers per stratum with 77 subs/ha and the Carola (54 subs/ha) do not show significant population percentages with savings $>2 \%$, despite being the neighborhoods closer to the the developments made.

\section{CONCLUSION}

Results show the highest percentage of time savings registered was $12 \%$ in the La Asuncion neighborhood, which has 40 subs/ha and a beneficiary population of $5 \%$, reaching $10 \%$ of the population with savings of up to $8 \%$. It should be noted that the neighborhood with the highest number of subscriptions per hectare, La Argentina with $81 \mathrm{subs} / \mathrm{ha}$, does not receive travel time savings larger than $2 \%$. The neighborhood of Laureles with 26 subs/ha, reached time saving percentages higher than $2 \%$ which means it is the area with maximum advantage in time savings given area size and amount of inhabitants.

Finally, urban territorial accessibility is a powerful instrument for calculating average travel times in a city's road network. Likewise, it helps identify mobility benefits and verifiable savings in time and distance that new road infrastructure will create by calculating savings gradient. It becomes a valuable instrument for companies responsible for $\mathrm{BL}$ assessment.

\section{ACKNOWLEDGEMENTS}

Engineer Diego Julian Perilla is expressly thanked for the advances made in his Master's Thesis that allowed complementing this research study. Thanks also to the Sustainable Mobility office of the National University of Colombia, Manizales.

\section{REFERENCES}

Aguirre, R., 2016. [ \$20thousand 281 million, for valuation in La Carola]. La Patria. http://www.lapatria.com/ node $/ 314860$

Anonymous, 2017. Process detail: INV-L-001-2017. INVAMA, Manizales, Colombia.

Boisjoly, G. and A.M. El-Geneidy, 2017. The insider: A planners perspective on accessibility. J. Transp. Geogr., 64: 33-43.

Escobar, D.A., J.M. Holguin and J.D. Zuluaga, 2016. [Accessibility of ambulance centers and hospitals providing emergency services and their relationship with spatial inequality case study Manizales Colombia In Spanish)]. Rev. ESPACIOS, Vol. 37,

Escobar, D.A.G. and F.J.O. Garcia, 2012. [Diagnosis of Urban Mobility in Manizales]. National University of Colombia, Bogota, Colombia, ISBN:978-958-761-128-1, (In Spanish).

Garcia, D.A.E. and C.F.U. Bonells, 2014. [Territorial accessibility: Instrument for urban and regional planning (In Spanish)]. Tecnura, 18: 241-254.

Geurs, K.T. and B.V. Wee, 2004. Accessibility evaluation of land-use and transport strategies: Review and research directions. J. Transp. Geog., 12: 127-140.

Geurs, K.T. and J.R.R.V. Eck, 2001. Accessibility measures: Review and applications evaluation of accessibility impacts of land-use transport scenarios and related social and economic impacts. Netherlands National Institute for Public Health and the Environment, Netherlands, Europe. https://www.rivm.nl/bibliotheek/rapporten/40850500 6.pdf. 
Giraldo, R., 2002. [Introduction to geostatistics-theory and application]. Master Thesis, Department of Statistics, National University of Colombia, Bogota, Colombia. (In Spanish)

Gulhan, G., H. Ceylan, M. Ozuysal and H. Ceylan, 2013. Impact of utility-based accessibility measures on urban public transportation planning: A case study of Denizli, Turkey. Cities, 32: 102-112.

Handy, S.L. and D.A. Niemeier, 1997. Measuring accessibility: An exploration of issues and alternatives. Environ. Plann. A, 29: 1175-1194.

Hansen, W.G., 1959. How accessibility shapes land use. J. Am. Inst. Plann., 25: 73-76.
Ingram, D.R., 1971. The concept of accessibility: A search for an operational form. Reg. Stud., 5: 101-107.

Ochoa, O.B., 2011. Betterment levy in Colombia: Relevance, procedures and social acceptability. Land Lines, 23: 14-19.

Pirie, G.H., 1979. Measuring accessibility: A review and proposal. Environ. Plann. A, 11: 299-312.

Preston, J. and F. Raje, 2007. Accessibility, mobility and transport-related social exclusion. J. Transp. Geogr., 15: $151-160$.

Vega, A., 2011. A multi-modal approach to sustainable accessibility in Galway. Reg. Insights, 2: 15-17.

Weibull, J.W., 1976. An axiomatic approach to the measurement of accessibility. Reg. Sci. Urban Econ., 6: 357-379. 